\title{
CANAÃ dos CARAJÁs: \\ UM LABORATÓRIO SOBRE AS CIRCUNSTÂNCIAS DA URBANIZAÇÃO, NA PERIFERIA \\ GLOBAL E NO ALVORECER DO SÉCULO XXI
}

\section{CANAÃ DOS CARAJÁS:}

A LABORATORY STUDY CONCERNING THE CIRCUMSTANCES OF URBANIZATION, ON THE GLOBAL PERIPHERY AT THE DAWN OF THE $2 I^{\text {ST }}$ CENTURY

Ana Cláudia Duarte Cardoso a, E, F

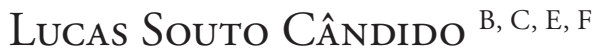

Universidade Federal do Pará, Programa de Pós-Graduação em Arquitetura e Urbanismo, Belém, PA, Brasil

Ana Carolina Campos de Melo a, E, F

Universidade Federal do Pará, Programa de Pós-Graduação em Economia, Belém, PA, Brasil

R E S U M O : Este artigo aborda o processo de crescimento urbano de Canaã dos Carajás, jovem cidade amazônica. A análise é estruturada dialeticamente segundo a interpretação lefebvriana de níveis da realidade social. O nível global captura o impacto de atividades capital-intensivas (mineração, pecuária e monocultura) na conexão entre o local de produção e o mercado global; o nível misto explica como a urbanização inspirada em processos globais foi mediada por grupos sociais locais; e o nível local revela como pontos cegos na compreensão dos processos em curso comprometem o fortalecimento da diversidade e levam à exclusão dos grupos sociais que mais dependem da terra e da natureza viva. Conclui-se que é necessário articular formulações contemporâneas sobre urbanização aos estudos sobre urbanização brasileira, a fim de explicitar a forma seletiva como as modernizações acontecem e se constituem em novas formas de colonização, sempre que as oportunidades econômicas elaboram as questôes socioambientais de modo conservador.

P A L A V R A S - C H A V E : urbanização; modernização; impactos da mineração; Amazônia; Canaã dos Carajás.

A B S T R A C T: This article addresses the processes of urbanization and urban sprawl in Canaã dos Carajas, a small relatively recent Amazonian municipality. The analysis is dialectically structured according to Lefebvre's interpretation of the levels of social reality. The global level captures how capital-intensive activities (mining, ranching, and monoculture) have impacted the connection between the place of production and the global market. The mixed level explains how local social groups, inspired by global processes, have mediated urbanization. The local level demonstrates how blind spots in understanding the ongoing processes have impaired the strengthening of diversity, and led to the exclusion of social groups that most depend on the land and nature. We conclude that it is necessary to articulate contemporary formulations and studies on Brazilian urbanization so as to demonstrate the selective manner in which modernization takes place and is constituted in new forms of colonization, whenever economic opportunities formulate socioenvironmental issues in a conservative manner.

KEYW O R D S : urbanization; modernization; mining impacts; Amazon; Canaã dos Carajás.

Contribuição de cada autor/a: A. fundamentação teórico-conceitual e problematização; B. pesquisa de dados e análise estatística; C. elaboração de figuras e tabelas; D. fotos; E. elaboração e redação do texto; F. seleção das referências bibliográficas.

DOI: https://doi.org/10.22296/2317-1529.2018v20n1p121 


\section{A PESQUISA: O PANO DE FUNDO E O ESCOPO}

A efervescência do debate sobre a urbanização contemporânea tem exposto as contradições e encruzilhadas dos estudos sobre o tema, com crescente nível de incerteza e diversidade de processos. Pesquisas de grande envergadura ou apoiadas por organismos internacionais apontam tendências que são apresentadas com veemência por seus autores, na expectativa de oferecerem a última palavra sobre os processos territoriais contemporâneos (PECK, 2014). Esse é o caso de pesquisadores neo-lefebvrianos envolvidos em um projeto de pesquisa dedicado ao tema da urbanização planetária, cujos textos adotam casos norte-americanos e europeus para sustentar a tese de que o processo contemporâneo de urbanização está produzindo uma estrutura de abrangência planetária, que se articula às transformaçôes e dinâmicas de desenvolvimento, e que são marcadas, sobretudo, pela intensificação das condiçôes de desigualdade socioespaciais, observadas de modo generalizado em diversas escalas. Por este motivo preconizam a criação de uma nova epistemologia do urbano capaz de universalizar o conceito e oferecer fundamentos para a emergência de uma teoria urbana critica renovada (BRENNER, 2013; 2014; BRENNER; SCHIMDT, 2015). No outro extremo, pesquisadoras ativistas destacam casos indianos e sul-africanos em defesa de uma abordagem anticolonialista, ou seja, há a necessidade de construção de novos conceitos para a caracterização dos processos vivenciados no Sul Global, face à forte contaminação do debate corrente pelas formas de pensar e pelas concepçôes de desenvolvimento hegemônicas (WATSON, 2009; ROBINSON, 2011; ROY, 2011).

Outros autores caracterizam a cidade contemporânea como um ambiente cada vez mais fragmentado e assimétrico no que diz respeito à experiência dos (ou exposição aos) chamados conflitos socioambientais. Tais autores reconhecem que muito da preocupação com questôes ambientais perdeu-se no esverdeamento das formas de produção, em nada afetando as práticas predatórias, de forte impacto social e ambiental, intrínsecas à matriz de desenvolvimento capitalista. Tais práticas assumem o controle e destruição da natureza como uma forma de dominação técnica e racional e, portanto, genuinamente aceitável (SMITH, 1988), ao mesmo tempo que impóem seus impactos aos grupos sociais mais vulneráveis (ACSELRAD, 2001; 2010a). Outra direção de análise discute a vinculação de raízes da fragmentação e desigualdade nas cidades dos países do Norte Global às metamorfoses mais recentes do capitalismo. Nesta linha, autores que adotaram o rótulo de "cidade neoliberal" para a cidade contemporânea (PECK, 2014) são acusados de simplificação por autores que dizem que o cenário atual não reedita práticas da fase liberal (STORPER, 2016; LE GALÈS, 2016). Neste ponto reforçam que as teses sobre quanto as práticas neoliberais originadas nos países do Norte não podem ser comparadas com os seus desdobramentos em países do Sul Global (ROBINSON; PARNELL, 2011), dadas as especificidades e a diversidade de formação histórica, econômica e social vividas nesses lugares. Stoper (2016) destaca a forma como o Estado contemporâneo foi cooptado por oligarquias e plutocracias e como a prática do liberalismo econômico (o laissez-faire) geram resultados sobre a urbanização muito diferentes daqueles obtidos através da mediação estatal sobre as falhas da livre concorrência, por meio de regulação e de intervençôes baseadas na realidade empírica, que contribuíram para a transformação das sociedades europeias no século XIX. 
Neste artigo procuram-se pistas sobre como esse mosaico de posicionamentos pode ajudar na compreensão do fenômeno de crescimento urbano, e da forma peculiar como se reorganiza o território no sudeste paraense, a partir do foco na cidade de Canaã dos Carajás. Nessa região a provisão de infraestrutura para apoio logístico de dinâmicas globais (mineração, pecuária, monocultura) gerou uma nova articulação entre cidades médias e pequenas com vilas e tipologias de uso e ocupação do solo de apoio a tais atividades (company towns, distritos industriais, alojamentos, centros logísticos). Parte-se de uma abordagem lefebvriana de que há uma relação dialética entre os níveis da realidade social (LEFEBVRE, 2008[1970]), e de que é preciso articular processos globais, mistos e locais para compreender as diversas camadas que compóem esse território, e identificar como elas se reportam às diferentes concepçóes teóricas elencadas, ainda que bastante modificadas pela forma também peculiar de como os processos contemporâneos em tela são adaptados pela sociedade brasileira.

Importantes contribuiçóes advindas dos campos da Sociologia (NUNES, 1997; BAUMAN, 2001), da Geografia (HARVEY, 2013[1982]; SANTOS, 2008[1979]), da Arquitetura e Urbanismo (MUXÍ, 2004; LOGAN; MOLOTCH, 1987) e da Economia Política (POLANYI, 2000[1945]; HARDT e NEGRI, 2004) para o campo dos estudos urbanos muito auxiliaram o percurso metodológico desta pesquisa, ao permitirem a captura dos processos políticos e socioespaciais brasileiros e universais, que tangenciam as grandes narrativas e melhor revelam as peculiaridades da urbanização que acontece na fronteira periférica que Canaã dos Carajás representa nesta virada do século.

Este artigo recebe insumos de açóes de pesquisa e assessoria técnica desenvolvidas no decorrer de dois anos no município e que tiveram como objetivo avaliar os impactos da mineração na sede municipal e fortalecer a gestão local. Apoiou-se em documentação disponível sobre a cidade, na interlocução estabelecida com gestores, profissionais liberais, técnicos da Vale S.A., em seminários, reuniôes de trabalho e entrevistas, e em sucessivos levantamentos de campo que a cada etapa venceram lacunas específicas: a produção de cartografias capazes de objetivar processos, a investigação da percepção da população por meio de entrevistas abertas e, posteriormente, a aplicação de entrevistas estruturadas por toda a cidade, estas últimas em fase de consolidaçáo. Alguns desses insumos, especialmente os relatos, foram usados para construir a narrativa deste texto que contrapóe o processo de urbanização em curso naquele município ao debate teórico corrente, a partir da exposição das camadas que correspondem às esferas da vida, de modo a iluminar pontos cegos e superposiçóes necessárias para a adequada compreensão do contexto em discussão.

\section{O NÍVEL GLOBAL: A CONSTITUIÇÃO DE UM NOVO TERRITÓRIO}

O plano global só pode ser compreendido a partir do processo histórico de conversão da floresta tropical úmida em área de fronteira de expansão capitalista e (trans)formação social da região. Isso pressupóe a diferenciação das concepçôes de desenvolvimento aplicáveis à área de estudo que, no caso da Amazônia, evoluíram da completa integração com a natureza das populaçôes originárias para a abertura da região como fronteira para a expansão do capital (HECKENBERGER, 2009; 
1 Criada em 1948, foi responsável por uma geração de teorias regionais de inspiração keynesiana, baseadas na ideia de que 0 desenvolvimento regional não poderia ser garantido através da livre ação das forças de mercado. Logo caberia ao Estado corrigir as desigualdades regionais e prover infraestrutura necessária para a efetivação do projeto de modernização do país (LEITÃO, 2009).
BECKER, 2013). Esta última fase, caracterizada por uma visão industrialista, é marcada por uma profunda ruptura com as formas de interação com a natureza secularmente praticadas na Amazônia, onde ela participava e codeterminava a atividade produtiva como substância viva (COSTA, 2009). No entanto, de acordo com a concepçáo desenvolvimentista que gestou o Programa Grande Carajás (PGC), a natureza passou a ser vista como matéria-prima objetivada no processo industrial, tratada "na sua condição mediata, como matéria genérica intercambiável e substituível” (COSTA, 2009, p. 42), e não como elemento ativo, capaz de entrelaçar conhecimento tradicional e inovação baseada nos potenciais locais e nos saberes socialmente construídos.

O PGC foi pensado nos anos 1970 como ação estratégica para a garantia do controle estatal sobre a maior reserva polimineral do mundo, abrangendo: a produção de energia a partir da Usina Hidrelétrica (UHE) Tucuruí; a extração do minério de ferro na província mineral de Carajás; o beneficiamento de bauxita em Barcarena; a construção de portos em Barcarena e em São Luís, da ferrovia Carajás-São Luís e de estradas municipais; e a implantação de assentamentos rurais para produção de alimentos para o efetivo de mão de obra envolvido no projeto, na área hoje correspondente ao município de Canaã dos Carajás (COELHO, 2014). A ação Estatal veio coibir as práticas ilegais de extração de minérios e gemas na região, mas esta era apenas uma das vertentes do projeto de modernização. Apoiada nas análises da Comissão Econômica para a América Latina e Caribe (CEPAL)1 a ação do Estado se deu a partir de grandes empréstimos externos, contratados durante o regime militar. Contudo, tratava-se de uma nova fase de colonização, a industrial, estabelecida após tantas outras já vividas na região durante o estágio mercantil do capitalismo (missionária, pombalina, dos aviadores) (BECKER, 2013; CARDOSO et al., 2016).

Somente a partir desse contexto é possível compreender os arranjos implementados complementares estabelecidos entre as macropolíticas ambientais e as de extração mineral durante os anos 1990, em cujo âmbito a Floresta Nacional (FLONA) de Carajás foi criada para garantir a integridade da área de lavra das primeiras minas operadas pela então estatal Companhia Vale do Rio Doce (CVRD). Em que pesem os benefícios da política ambiental em um contexto de fronteira, a criação de uma floresta nacional viabilizou o afastamento tanto das populaçóes nativas quanto dos aventureiros e o avanço sobre o território não protegido da ação empresarial fomentada pelos incentivos públicos da Superintendência do Desenvolvimento Amazônia (SUDAM), sem que nenhuma atenção fosse dada às transformaçóes sociais e ambientais desencadeadas na escala em que a vida cotidiana se desdobrava (FUNDAÇÃO DE AMPARO E DESENVOLVIMENTO DA PESQUISA, 2016).

Não bastando toda a transformação resultante dessas iniciativas, outras funcionalidades foram encontradas no desbravamento desse território, como o direcionamento de frentes migratórias, seja para aliviar a crise decorrente da seca na região nordeste, seja para constituir uma massa móvel de trabalhadores necessária para expansão das forças urbano-industriais deslocadas para a fronteira (BECKER, 1982). A máo de obra ociosa no país foi direcionada para as grandes obras de infraestrutura (hidrelétricas, ferrovia, portos, rodovias) e para a exploração de garimpos, como o de Serra Pelada, localizado a $140 \mathrm{~km}$ da mina de Carajás. O ritmo e velocidade de transformação foram avassaladores. Os desbravadores (migrantes pioneiros de baixa qualificação, mas com muita disposição para perseguir o enriquecimento rápido), 
vistos à época como heróis, rapidamente preencheram as lacunas sociais existentes naquela estrutura social que estava em gênese.

Em meio aos líderes militares, como o Coronel Sebastiāo Curión , engenheiros, trabalhadores das frentes de obra, aventureiros, grileiros, etc., foi composta uma divisão social do trabalho e foram introduzidos elementos da velha "gramática brasileira" de relacionamento entre Estado e sociedade, apontados por Nunes (1997): o clientelismo, o corporativismo, o insulamento burocrático (caracterizado pelo temor da participação popular no processo decisório) e o universalismo de procedimentos da burocracia federal, o qual definia regras genéricas para todo o território nacional, desconsiderando completamente as especificidades dos processos nas diversas regióes e, particularmente, a revoluçáo que estava em curso na Amazônia ${ }^{3}$. Era óbvia a orientação industrial e modernizadora da açấo federal, dentro de uma concepção de desenvolvimento que assumia como referência e parâmetro os procedimentos das sociedades capitalistas industrializadas, e dada a crise econômica dos anos 1980, os investimentos do PGC tornaram-se estratégicos para a viabilização da produção visando às exportaçóes e ao equilíbrio da balança comercial brasileira.

Contudo, do ponto de vista social, ainda que o Estado procurasse agir de modo impessoal a partir de procedimentos burocráticos, a gramática política brasileira rapidamente se estabeleceu nesse novo ambiente amazônico, à medida que uma burguesia era formada rapidamente com vantagens políticas e econômicas negociadas antes mesmo de sua chegada na regiáo, como prêmio ao seu envolvimento no processo de integração nacional. Essa nova burguesia recebia o controle da terra e a interlocução privilegiada com o poder como bônus. A fragilidade das instituiçóes estatais em controlar as açôes dos velhos e novos atores na regiāo tornou leis e regras algo remoto e favoreceu o uso da violência e a subordinação dos demais grupos sociais, comprometendo a criação de uma esfera pública e o fortalecimento de entidades que garantissem a visibilidade de todos os atores interagindo naquele contexto (pesquisas de campo, 2015, 2016).

Como temas relacionados às questóes fundiária, ambiental e social, estavam fora da pauta desenvolvimentista todos os conflitos socioambientais gerados, tais quais são caracterizados atualmente pelo debate sobre justiça socioambiental (ACSELRAD, 2005; 2010a; 2010b; ACSELRAD; MELLO; BEZERRA, 2009). Tornaram-se, pois, pontos cegos, invisíveis aos agentes envolvidos nas negociaçôes relacionadas à produção, que se interessavam nos quantitativos de exportação. Tal cegueira foi favorecida pela carência de formulaçóes conceituais que dessem conta da diversidade e das sobreposiçóes de racionalidades que ocorriam na região onde, apesar do apelo feito ao setor privado (financiamentos, isençóes, concessão de terras), manteve-se a grande incompreensão das práticas históricas baseadas pela cooperação entre homem e natureza e na grande dependência dos investimentos públicos para que qualquer conversão acontecesse (SILVA; DINIZ; FERREIRA, 2013).

Rapidamente o poder político foi concentrado nas mãos das novas elites locais (oriundas dos estados do centro-sul), que detinham monopólios importantes em função da quantidade de terras que possuíam e do uso da violência como forma de pressão política e social, beneficiadas pelo fato de o Estado moderno ser visto como o lugar da autoridade. $\mathrm{Na}$ medida em que as instâncias de poder local e regional foram cooptadas pelas novas elites, especialmente pela municipalização de pequenas vilas em crescimento (como no caso da emancipação de Parauapebas do município de
2 Major Curió, como ficou conhecido Sebastião Rodrigues de Moura, teve forte atuação no Sul do Pará durante o Regime Militar. $\mathrm{Na}$ década de 1980, além de participar ativamente das ações de repressão à Guerrilha do Araguaia, foi responsável por comandar a exploração de ouro na região de Serra Pelada, que naquele momento já contava com cerca de 30 mil garimpeiros.

3 Ainda que a universalização de procedimentos tenha sido uma estratégia para a universalização de acesso a direitos, perdeu eficácia na medida em que deixou para as arenas regional e local a resolução de conflitos históricos (ex.: gestão fundiária e controle urbanístico). 
4 A exploração do cobre deu ao município de Canaã dos Carajás a segunda colocação como maior exportador do estado do Pará entre 2009-2011 (PARÁ, 2014). Além disso, a quantidade e a qualidade do minério de ferro encontrados na área do S11D (a maior mina de ferro a céu aberto do mundo, e que conta com um minério de altíssimo teor) levaram à aplicação de investimentos na ordem de 17 bilhões de dólares para a viabilização do projeto S11D (VALE S. A., 2016).
Marabá, e posteriormente a separação de Canaã dos Carajás do município de Parauapebas), o esperado universalismo de procedimentos da burocracia estatal deu lugar ao clientelismo e corporativismo. Melo (2015) e Fernandes et al. (2016) apresentam investigação da transformação de empresários financiados pela SUDAM em empreendedores imobiliários e apoiadores de grupos políticos nesses municípios.

Um último fato ocorrido na década de 1990 tem grande relevância para a compreensão do plano global: o processo de privatização das estatais brasileiras. Dentre elas, destaca-se o caso da CVRD, ocorrida em 1997, e que se torna a partir de então a terceira maior companhia mineradora do mundo, surfando por um período de quinze anos de crescimento viabilizado pela grande valorização das commodities minerais, em resposta ao ritmo de crescimento econômico observado na China (COELHO, 2014). A nova escala de investimentos e o novo ritmo de transformaçôes alteraram significativamente a dinâmica econômica do município de Canaã dos Carajás, interligando-o diretamente às flutuaçôes do preço do minério praticadas no mercado chinês, a princípio com a exploração do minério de cobre pelo Projeto Sossego nos anos 2000, e, posteriormente, com a implantação do projeto S11D, dedicado à exploração do minério de ferro ${ }^{4}$. A interligação direta entre um pequeno município de área de fronteira e o dinâmico mercado chinês, a exemplo da discussão tratada sobre as novas configuraçóes territoriais contemporâneas, traz à baila o debate sobre o fim da era da metrópole como um entreposto de controle entre as regióes de comando e espaços periféricos (MOURA, 2012). E ratifica a tese de Muxí (2004) sobre o quanto a crescente especialização das cidades cria uma rede global pautada por relaçôes empresariais e as coloca dentro de um novo marco de relaçóes, no qual o pertencimento a essa rede global se sobrepóe à importância de se posicionar articuladamente com outras cidades nos contextos nacional e regional. Nessa perspectiva, observa-se a manifestação do fenômeno da urbanização extensiva apresentado por Monte-Mór (1994; 2015), que dialoga com a tese da urbanização planetária de Brenner (2014), porém, é muito mais responsiva às especificidades do contexto amazônico periférico ao contrapor à universalização do consumo a necessidade de universalizaçáo de cidadania e de enraizamento das políticas de desenvolvimento.

Nos anos de pesquisa dedicados ao caso de Canaá, observou-se que, subitamente, as pequenas localidades de apoio às açóes do antigo PGC foram guindadas à condição de periferia distante de centros globais pelo simples fato de estarem próximas às áreas de produção de commodities reguladas pelo mercado global. Há convergência entre esta dinâmica e o que Robinson (2011) considera como o movimento do grande capital em direção aos países do Sul. A autora afirma existir nesses locais uma espécie de "neoliberalismo extrativo", onde a dinâmica neoliberal opera, mas cujo centro de comando se mantém a quilômetros de distância. Ainda segundo a autora, nos países do Sul Global, as dinâmicas regidas pelo capital não se alastram por todo o território de forma homogênea, mas se concentram em pontos específicos, como é o caso das zonas de exploração de recursos naturais.

Em Canaã dos Carajás, observa-se que a modernizaçáo acelerada e pontual caracteriza bem a interdependência entre os dois circuitos da economia urbana apresentados por Santos (2008[1979]), em que a mineração, a produção imobiliária e a grande pecuária compóem um circuito superior, e as práticas de produção familiar (agricultura urbana, apicultura, artesanato, etc.) ou de varejo e serviço informal compóem um circuito inferior. Além disso, foram dadas as condiçóes para que uma 
completa reorganização do território acontecesse, na medida em que os processos já em curso foram cooptados pelas novas lógicas (a busca do assalariamento, especialização da mão de obra, a visão utilitarista do território como base para a produção, a transformação da cidade em mercadoria).

De uma perspectiva lefebvriana (LEFEBVRE, 2000; 2008[1970]), observa-se que o sentido da cidade como lugar do encontro (de pessoas, mercadorias, saberes) foi suplantado pelo sentido da produção e exploração visando ao beneficiamento de atores que se localizam em áreas distantes (pesquisas de campo, 2015, 2016). Nesta pesquisa compreendeu-se que a implosão da antiga vila, metamorfoseada ${ }^{5}$ em cidade, e a explosão das estruturas de suporte ao novo modo de produção por todo o município (alojamentos, centros logísticos, área de operação da mina, barragens, estradas, etc.) valorizaram rapidamente as antigas terras rurais e favoreceram a imposiçâo da lógica urbana especulativa sobre a comercialização das terras rurais, promovendo a transformação das áreas produtivas em conjuntos de chácaras de final de semana próximas às novas estradas na porção norte-oeste do município. Ao sul da sede municipal, chácaras de habitação precária começam a emergir, em direção às áreas de pequena produção, que se concentram próximo à divisa com o município de Água Azul do Norte, enquanto a leste da sede municipal e do município uma única fazenda define as condiçóes de uso e ocupação da terra (Figuras 1 e 2).

Figura 1: Configuração territorial do município de Canaã dos Carajás

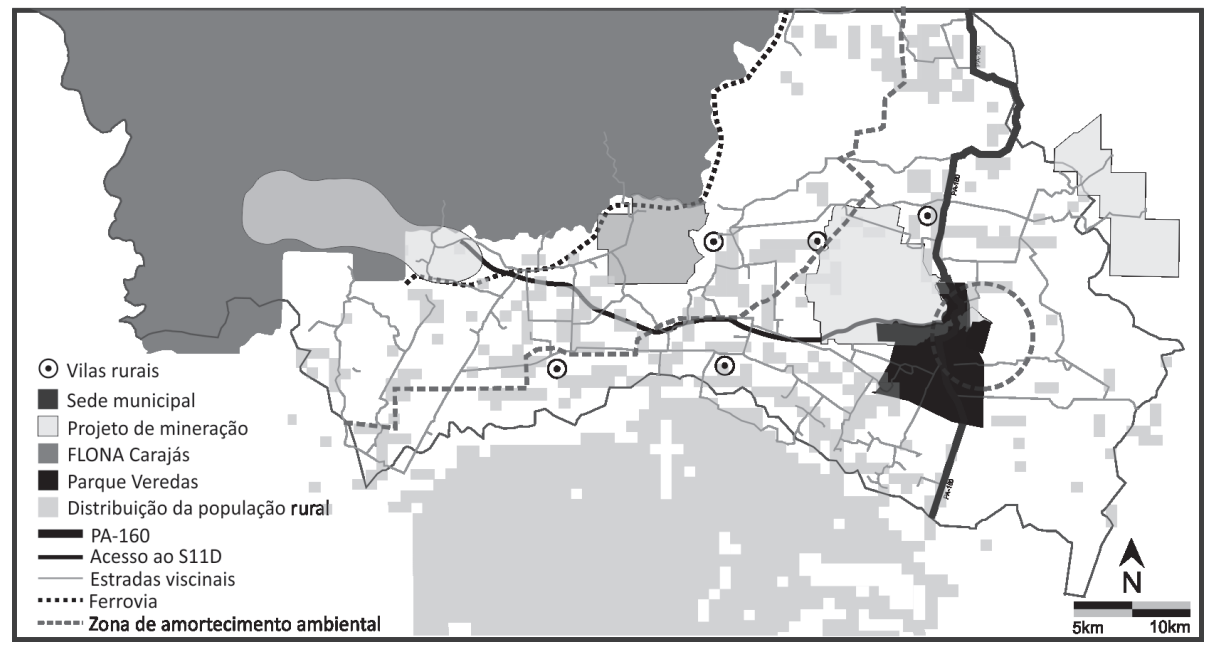

Fonte: Elaborado por Lucas Cândido com base em Instituto Brasileiro de Geografia e Estatística (2010) e Diagonal Urbana (2011).
5 Neste texto, a alusão ao fenômeno da metamorfose de um tipo, baseiase nas ferramentas de análise oferecidas pelas escolas de morfologia urbana. 
Figura 2: Esquema com as direções das dinâmicas de expansão da sede municipal

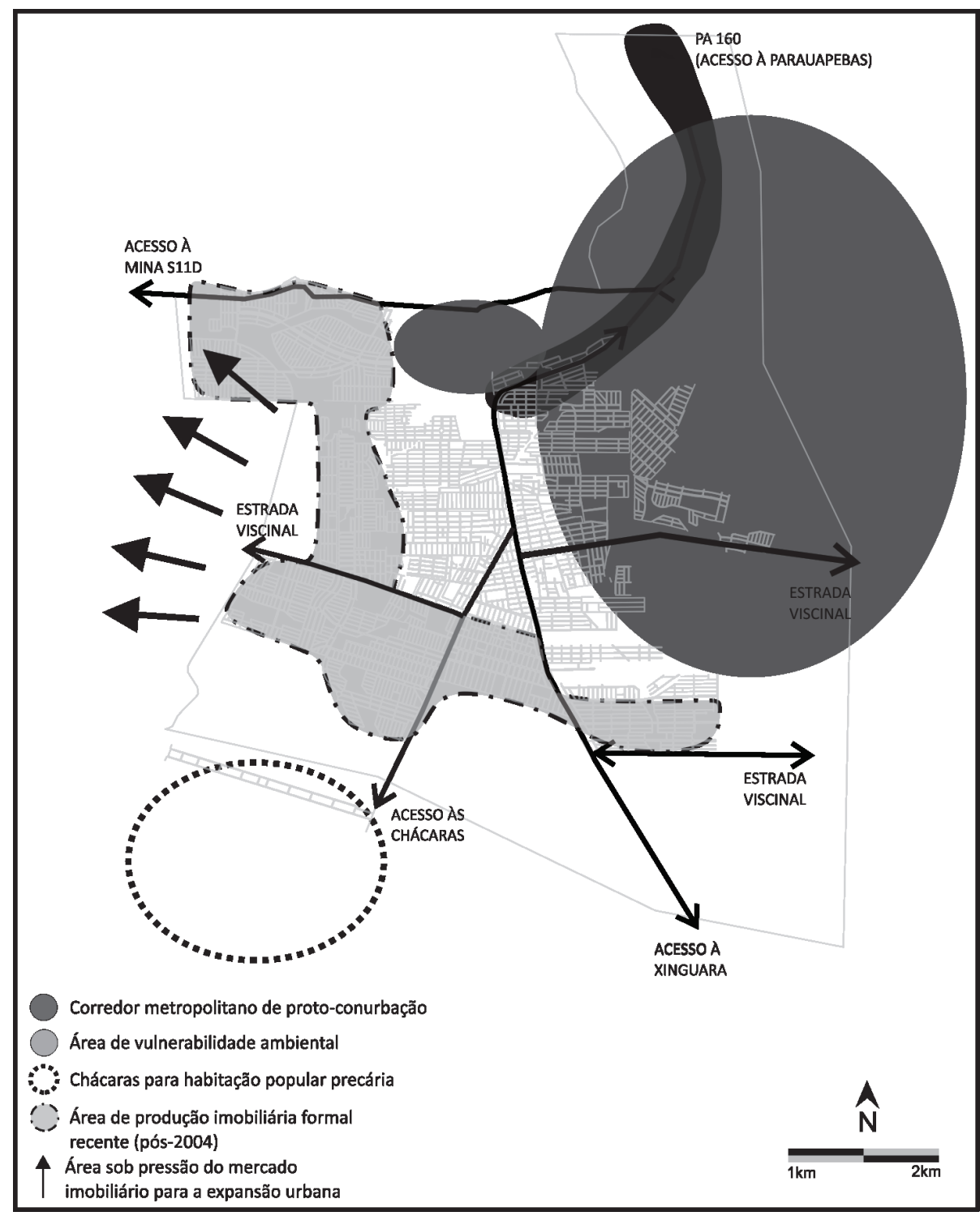

Fonte: Elaborado por Lucas Cândido a partir do Mapa de arruamento e perímetro urbano (PREFEITURA MUNICIPAL DE CANAÁ DOS CARAJÁS, 2012; 2015).

No alvorecer do século XXI, a produção do espaço urbano no sudeste do Pará ainda é resultado da ação oligárquica e do desrespeito à regulação federal que regulamenta o parcelamento do solo urbano, à gestão ambiental e urbanística e/ou às competências de instituições governamentais (regionais e locais), questôes que são melhor enquadradas na esfera lefebvriana de vida mista, abordada a seguir.

\section{O NíVEL MISTO: A GÊNESE DA CIDADE}

A introdução de novas paisagens financeiras, viabilizadas pela exploração mineral transnacional (ex: centros comerciais, condomínios fechados), desencadeou uma explosão populacional e um processo de crescimento urbano completa- 
mente novos na cidade que se mostram capazes de articular redes globais (a ordem distante) até a esfera mais imediata da casa (a ordem próxima) (LEFEBVRE, 2000; 2008[1970]). Toda a transformação urbana investigada foi tanto impulsionada pela ação de uma empresa mineradora transnacional quanto foi fruto da ação intensa de fazendeiros, proprietários de terra, políticos locais, migrantes e pioneiros, que atuam a partir de uma racionalidade própria, envolvendo muitas vezes o descumprimento das leis ambientais e urbanas, o uso de relaçôes de influência e informaçôes privilegiadas, o entrelaçamento entre seus interesses privados e açôes do poder público, práticas de espoliação, coerção e degradação do ambiente natural, dentre outras práticas de pilhagem social e ambiental que são assumidas nesses contextos como condutas naturais.

Desse modo, o setor imobiliário, também articulado ao sistema financeiro internacional, paulatinamente teria transformado a cidade de Canaã dos Carajás em uma possível variante da máquina de crescimento, descrita por Logan e Molotch (1987) para as cidades norte-americanas dos anos 1980, atraído pela expectativa de transbordamento dos lucros impulsionados pelo boom da mineração. Contudo, como Ferreira (2003) demonstra que a teoria da máquina de crescimento, no caso brasileiro, aplica-se apenas às áreas formais, nesta pesquisa constatou-se que os agentes citados compreenderam que era necessário produzir áreas formais em Canaã dos Carajás por meio da expansão dirigida da malha urbana. Esse processo ocorreu em dois ciclos distintos de expansão: a) um primeiro, no qual os agentes locais pioneiros, proprietários de terra, empresários e fazendeiros, beneficiaram-se do acesso à informação privilegiada sobre a instalação do Projeto Sossego pela empresa Vale S.A. e foram capazes de articular e iniciar um processo de expansão urbana improvisado e fortemente especulativo; b) um segundo ciclo, liderado por empresas imobiliárias de capital nacional e regional, associadas às securitizadoras internacionais que gradativamente substituíram os primeiros agentes (Figura 3).

Figura 3: Esquema com crescimento populacional, expansão da malha urbana e relação entre a malha urbana construída versus ocupação efetiva dos lotes
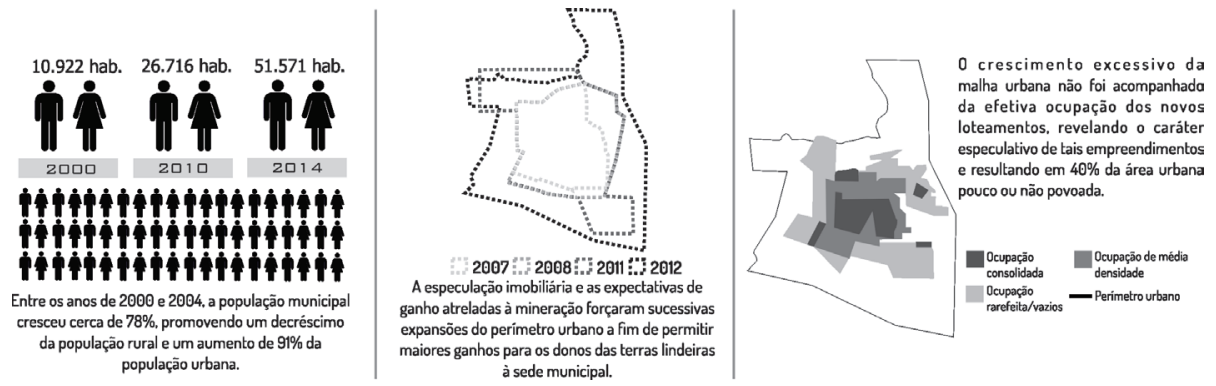

Fonte: Fundação de Amparo e Desenvolvimento da Pesquisa (2016).

As peculiaridades do funcionamento do poder local permitiram que se estabelecesse a coexistência entre práticas e temporalidades distintas na região, um mosaico socioterritorial em que convivem o capitalismo financeirizado, o capitalismo moderno industrial, o capitalismo mercantil e modos de produção e reprodução da vida em que o capitalismo não prevalece, relaçóes mais próximas aos princípios de reciprocidade e da troca (POLANYI, 2000[1945] $)^{6}$.
6 São tomadas aqui como relações de reciprocidade as práticas cotidianas da população mais pobre que manifestam formas de relações econômicas não mediadas pelo mercado (partilha, cooperação). São frequentemente observadas nas trocas entre familiares, parentes e cooperativas, e em atividades como a agricultura urbana, o extrativismo, o artesanato e as feiras de rua. Além disso, são comuns na região as negociações de troca de serviço por produtos (passagem de ônibus intermunicipal paga com um cacho de banana), ou simplesmente relações de solidariedade como a carona amiga. 
As evidências empíricas obtidas confirmam os resultados de Melo (2015) para as cidades de Marabá e Parauapebas: de que o mercado imobiliário de Canaã dos Carajás também possui forte vínculo com agentes locais, cujo protagonismo é sustentado através da propriedade da terra; o que tem funcionado historicamente como base das relaçôes de poder tradicionais na regiāo (FERNANDES et al., 2016), constituídas desde as políticas de atração de empreendedores para a "ocupação" da região, mediante financiamento estatal, via projetos de colonização e incentivos fiscais operacionalizados pela SUDAM. Tais açôes constituíram uma estrutura fundiária baseada na privatização de terras e de sua concentração nas mãos de agropecuaristas, madeireiros, grileiros e outros grupos ligados ao capital industrial-financeiro, e colocaram as empresas madeireira e agropecuária dos anos 1960 na origem das atuais empresas imobiliárias (MELO, 2015). O vínculo entre essa geração de empresários com os novos negócios imobiliários é uma constatação-chave para a compreensão do funcionamento atual do mercado imobiliário local e das recentes transformaçóes do espaço urbano de Canaã dos Carajás. A transição e diversificação dos investimentos destes segmentos em direção ao setor imobiliário indica o papel central que a propriedade da terra assumiu com o projeto de modernização: uma forma de ativo financeiro para obtenção de rendas cada vez maiores (HARVEY, 2013[1982]).

Há duas características do recente processo de mudança de uso da terra nesse contexto: a) a conversão massiva de terras rurais em urbanas, já que a terra urbanizada pode obter maior remuneração; e b) a tendência de conectar a terra ao sistema financeiro. A pesquisa de campo revelou a articulação recente entre fundos de investimentos estrangeiros e a produção de empreendimentos imobiliários no sudeste paraense, inclusive em Canaã de Carajás. A coalizão do financeiro-global ao imobiliário-local retroalimenta as duas dinâmicas. De um lado, os fundos de investimentos captam recursos no mercado de capitais para viabilizar a extraordinária abertura de loteamentos urbanizados na regiáo, ao mesmo tempo que estes novos empreendimentos imobiliários passam a compor o portfólio de investimentos desses fundos, ampliando seus valores de mercado, mesmo que a expectativa de realização desses valores (com a venda dos lotes) náo seja concreta. Como resultado dessas estratégias de articulação, ocorreu um descolamento entre o processo de urbanização conduzido por investidores internacionais e empresários locais unidos pelo imperativo básico da acumulação (fácil) de capital, e as demandas concretas de construção da cidade, que vêm tornando seus habitantes, sobretudo, os mais pobres, completamente vulneráveis às contradiçóes que o processo de financeirização cria, quando associado à transformação do uso da terra, assunto que será discutido com mais detalhe na esfera da vida cotidiana, adiante no texto.

Os desdobramentos da dinâmica imobiliária nesse contexto revelam um movimento típico do espaço periférico e de fronteira, onde diversas temporalidades se (des) encontram em um mesmo território. Nesse contexto, coexistem o modus operandis da atividade industrial do século XX e as inovaçóes tecno-informacionais do paradigma tecnológico contemporâneo que operacionalizam as mudanças espaço-temporais associadas ao ritmo cada vez mais acelerado de circulação de capital, graças ao modo como a crescente participação do setor terciário moderno (serviços e informação), apoiada por aparatos tecnológicos (computadores), viabiliza a produção e reprodução dentro da rede a distância, e reduz a interaçáo dentro e entre os lugares de produção (HARDT; NEGRI, 2004). 
A demanda por trabalhadores altamente especializados e a adoção de tecnologias de última geração, para a operaçáo da mina S11D, intensificam a polarização do trabalho em Canaã dos Carajás. O mercado imobiliário se destina aos poucos profissionais qualificados empregados pela mineradora e suas terceirizadas (engenheiros, geólogos, técnicos), enquanto a massa migrante que foi atraída pela perspectiva de emprego se concentra em áreas ambientalmente frágeis ou nas áreas onde a terra é mais barata, em áreas de ocupação irregular e em moradias financiadas pelo programa Minha Casa Minha Vida. Durante o período de construção da mina, houve maior correspondência entre expectativa do setor imobiliário e mercado consumidor, quando foram atraídos 18.000 trabalhadores que acreditavam que o investimento em lotes nos novos loteamentos seria um bom negócio. Com a aproximação do início da fase de operação, há expectativa de fixação de menos de 100 trabalhadores diretos, esses qualificados, na cidade, e o bônus de um contingente de desempregados na cidade (informação obtida em reuniôes de trabalho com profissionais liberais, com gestores da Prefeitura Municipal de Canáa dos Carajás e com técnicos de projetos da Vale S.A. no município, realizadas em julho de 2015).

As transformaçôes espaciais na cidade foram pautadas pelos interesses de poucos e impostas verticalmente de maneira a consumar os ganhos para a elite latifundiária local, seguindo um modelo de apropriação incompleta de códigos e matrizes característicos de contextos exógenos. Esse crescimento fragmentado de Canãa dos Carajás, através dos novos conjuntos habitacionais, loteamentos e condomínios fechados, levou à fragmentação socioespacial da cidade, e gerou grandes distâncias espaciais e sociais, sem a contrapartida de espaço e serviços públicos. A elitização da sede já promove um movimento pendular (commuting) com a vila rural mais próxima, distante 15 $\mathrm{km}$ (vila Planalto), com chácaras localizadas ao sul (populares) e ao norte (ao longo da estrada que conecta Canaã dos Carajás e Parauapebas). Tais fatos indicam uma espécie de "proto-conurbaçáo" no eixo que liga as duas cidades, fenômeno avaliado como uma manifestação de processos tipicamente metropolitanos naquela realidade.

O processo de subdivisão municipal, em 1994, viabilizou o voto para escolha das representaçôes políticas, contudo, a possibilidade de escolha e decisão por parte da população não foi empecilho para a formação de uma elite oligárquica local. $\mathrm{O}$ abandono das terras pelos primeiros colonos permitiu o controle das oportunidades geradas pela dinâmica da mineração pelos controladores da terra e das condiçóes de seu parcelamento, indução de centralidades, uso e tipologias de ocupação do solo. As pesquisas de campo revelam que a fidelização das camadas socialmente mais vulneráveis a partir da venda de terra a longo prazo e o uso de lotes para pagamento de serviços agravaram a posição subalterna do pequeno, fortaleceu a atuação oligárquica das elites e tornou a reserva de terras para loteamentos posteriores muito mais lucrativa. As novas receitas da mineração (Imposto Sobre Serviços (ISS), royalties) e a acelerada urbanização dificultaram a compreensão global dos processos em curso e a necessidade de formação de um corpo técnico capacitado a gerenciar tamanhas mudanças. As providências tomadas pelo poder público - construção de escolas, postos de saúde e hospital e melhorias no sistema viário e na provisão de infraestrutura urbana - reverberam positivamente junto à população que enfrentou enorme precariedade anteriormente, mas não consegue avançar na transformação das condiçôes de vida para os novos migrantes (a decisão da localizaçấo e porte dos equipamentos é pautada mais pelos interesses de expansão e produção da cidade formal do 
que pelas necessidades da populaçáo). A força da propriedade privada como elemento estruturador da produção do espaço urbano resultou em exiguidade de espaços públicos de convivência e de representação político-civil na cidade. A cidade carece de espaços públicos e áreas verdes onde a população possa socializar, induzindo a transferência da vida pública das pessoas para ambientes semipúblicos e/ou privados (lojas, restaurantes, igrejas), cujos níveis de acesso dependem da renda e do pertencimento a grupos, o que engendra mais segregação e precariedade para as populaçôes mais vulneráveis que não têm voz para pautar a agenda municipal nem têm meios ou renda para se adaptar ao novo modo de vida.

Incapaz de atender às diversas dimensôes da trama da vida urbana, Canaã dos Carajás é descrita pelos moradores como a "cidade do trabalho". Ou seja, é uma cidade regida por interesses de mercado e na qual o cidadão atua (e vive), contrariando sua condição civil, como um consumidor (MUXÍ, 2004). Diferentemente do "lugar antropológico" descrito por Augé (1994), como o espaço capaz de entrelaçar o plano físico com as atividades que nele se desenvolvem, em Canaã vêm-se constituindo os espaços da supermodernidade que náo mediam os processos urbanos - são os "não-lugares" -, que impõem novas experiências e vivências de uma "tensão solitária".

Observa-se na cidade que os conflitos políticos não foram explicitados, e as práticas preexistentes foram suplantadas pela lógica da apropriaçáo privada, comprometendo a construção de qualquer instância de domínio público, de ordem espacial ou social. Por fim, a mediação de interesses dos diversos grupos sociais esteve sujeita a arranjos que mantiveram o poder e a autoridade concentrados nas mãos dos poucos que dispunham de algo a oferecer nos processos de barganha. A ineficácia da ação estatal também inviabilizou a difusão do universalismo de procedimentos típicos dos estados industriais modernos (NUNES, 1997). A esse respeito é preciso mencionar que o apoio da Vale $S$. A. à gestão municipal criou uma cultura de consultorias que, apesar de oferecer contribuiçôes reais ao município, sempre foram pouco compreendidas e internalizadas, seja no âmbito da administração, seja no âmbito da sociedade. Esse fato foi sempre agravado pela orientação metropolitana dos produtos dessas consultorias e pela pouca aderência das propostas às necessidades de grande parte da populaçấo excluída do circuito de operação da mineração ou das atividades de exportação.

A primazia do valor de troca no processo de expansão da malha urbana promoveu o contínuo abandono das antigas formas de apropriação do território (de caráter rural), e, a partir do parcelamento das antigas fazendas, viabilizou o afloramento de metamorfoses ou de fragmentos da forma urbana metropolitana do Norte Global nesta cidade de pequeno porte, por meio das morfologias espaciais geradas pelos novos arranjos produtivos e pela financeirização econômica (especialmente os loteamentos de alto padrão e condomínios fechados abertos na área de expansão desde 2013). Em um primeiro momento, a área central foi continuamente parcelada sem que houvesse uma regulação e/ou fiscalização quanto à provisão de infraestrutura básica (saneamento, asfalto, calçamento, arborização), resultando em áreas espacialmente pouco qualificadas e em uma malha viária extremamente desconexa e fragmentada que dificulta o deslocamento tanto dos pedestres quanto de motoristas. A recente ação de regularização fundiária e urbanística, viabilizada após a lei federal 11.952/2009 (BRASIL, 2009), promoveu a melhoria da infraestrutura nas novas áreas, mas pouco avançou na provisão de espaços públicos e na criação de novas centralidades. 
As espacialidades exógenas impuseram novos modos de vida cotidiana pautados pelo consumo, e novos modos de apropriação do espaço criando mutaçóes na articulação entre lugar, identidade e cotidiano (CARLOS, 2007), de modo a acelerar a velocidade de reprodução do capital. A rápida transformação das tipologias originais da cidade (pequenos casebres de madeira de implantação solta no lote, vias de pequeno porte) para as novas expressóes espaciais (casas de alvenaria em terrenos murados que chegam a custar um milhão de reais, prédios de cinco a oito pavimentos, grandes avenidas) atendem às demandas dos centros de poder e negligenciam a estabilidade e durabilidade do meio ambiente, que podem oferecer alternativas de subsistência à população e servir de instrumentos para redução das incertezas e dos conflitos derivados de tais mudanças (TUAN, 2013). Além disso, revelam também as dificuldades de se relacionar com o outro frente ao cenário de inversão de valores da cidade contemporânea, dada a contínua degradação das relaçóes de vizinhança e comunidade e a sua gradativa substituição pelo individualismo que acompanharam o “desenvolvimento" da cidade, conforme alerta Bauman (2001, p. 127):

[...] uma patologia do espaço público que resulta numa patologia da política: o esvaziamento e a decadência da arte do diálogo e da negociação, e a substituição do engajamento e mútuo comprometimento pelas técnicas do desvio e da evasão. "Não fale com estranhos" - outrora uma advertência de pais zelosos a seus pobres filhos - tornou-se o preceito estratégico da normalidade adulta.

\section{- NíVEL LOCAL: A ESFERA DA VIVÊNCIA COTIDIANA}

A correlaçáo de forças estabelecida a partir da entrada da mineração no município gerou a expectativa de contínua conversão do território à racionalidade do "progresso" e do "desenvolvimento", ainda que isso significasse a intensificaçáo dos conflitos socioambientais convenientemente mantidos como pontos cegos. A visibilização desses conflitos demanda abordagens de análise que articulem os processos manifestos nas diferentes escalas e revelem suas expressóes na esfera da vida cotidiana, explicitando como as negaçôes se articulam às estratégias de dominação e ideologias hegemônicas. É nessa escala que se observa como as novas configuraçôes (tipologias de uso e ocupação do território) interferem na vida das pessoas, qualificando-a como a melhor escala de resolução para revelar as travas ao transbordamento da riqueza circulante do circuito superior para o inferior (SANTOS, 2008[1979]).

A adoção de práticas produtivas de base industrial, atreladas ao capital financeiro e descoladas dos processos socioeconômicos preexistentes no município, introduziu uma oposição entre urbano e rural, por meio da gama de novas morfologias prático-sensíveis no território, até então desconhecidas na regiāo. Valores e formas de uso e ocupação do solo foram importados de contextos metropolitanos e estrangeiros, e impostos sobre este ambiente de matriz identitária rural, de maneira a depreciar as articulaçóes entre pessoas, território e práticas econômicas historicamente bem-sucedidas. A contaminaçáo das práticas locais por valores provenientes da ordem urbano-industrial, permeados pela lógica do consumo, abriu caminho para que as 
trajetórias de tempo lento (SANTOS, 2008 [1979]) de base rural, que privilegiavam as relaçôes de vizinhança e o valor de uso da terra e permitiam a consolidação do saber sobre o manejo da natureza, fossem estigmatizadas como atrasadas, e se rendessem ao discurso hegemônico de que existiria apenas um caminho para o desenvolvimento (FURTADO, 1974).

As rupturas negaram a diversidade socioespacial que emergiu na regiáo e ampliaram desigualdades que foram potencializadas pelas adaptaçóes espaciais unilateralmente direcionadas para o uso do automóvel e usufruto privado da cidade. O espraiamento da malha urbana favoreceu a metamorfose do padrão tradicional da rua como espaço de encontro e da diversidade, com qualidades espaciais adequadas às formas de deslocamento habituais da regiáo (pedestres e ciclistas), para um arranjo adaptado ao transporte individual, transformando a rua em elemento quase exclusivo de conexão entre a esfera da produção (trabalho) e a esfera do consumo, destituindo sua função de sociabilidade, ampliando distâncias e dificultando a locomoção da população mais pobre que habita a periferia, como mostra o relato de moradores abaixo:

Entrevista 01: Rapaz, o que eu acho que é difícil aqui é que tudo que a gente precisa tem que ir lá no Centro. Quando meu esposo tá aqui ele ainda me leva na motinha [...], mas quando ele não tá a gente vai de pé (moradora, agosto de 2016).

Entrevista 02: [E morar aqui longe do Centro, é muito difícil?] É muito difícil! Porque as vezes a gente precisa fazer alguma coisa urgente aqui, a gente tem que ir lá pro Centro. E como eu disse, ou é de bicicleta ou é a o pé. Aí a gente chega atrasado. Às vezes pra uma entrevista de emprego a gente tem que ir muito antes, a gente chega lá cheia de poeira. Agora tem asfalto, mas antes... Aí a gente chegava e tinha que arrumar um lugar pra ficar limpinho e na hora da entrevista tá todo arrumadinho. Sempre foi complicado aqui (moradora, agosto de 2016).

Desse modo, a ampliação da cidade de Canaã dos Carajás negligenciou os espaços públicos e áreas livres, os rios, os morros e as matas ciliares, homogeneizando a paisagem para ampliar a extensão das glebas urbanizáveis, e transferindo a socialização para os espaços privados. A alienação em relação à natureza (e às trilhas, cânions, cachoeiras, rios existentes no município) fortalece a demanda por fórmulas de lazer importadas da cidade global (o shopping center), obscurecem as potencialidades paisagísticas da região dentro e fora da cidade, que poderiam ser utilizadas como espaços de manutenção das práticas de lazer tradicionais, e impelem os moradores, conforme diversos relatos, a permanecerem em casa nas horas de lazer, ou mesmo se deslocarem até Parauapebas em busca de diferentes opçóes (o shopping center, o cinema), dado o "apagão" de espaços de sociabilidade que a cidade vivencia.

Alternativas à visão hegemônica passam despercebidas, graças ao descompasso entre o tempo de reprodução do capital (em constante aceleração) e o tempo de reprodução da vida. A voracidade das transformaçôes dificulta tanto a absorção gradativa quanto a compreensão global dos processos em curso pela população, alienada pela presunção de que pode atender as suas necessidades exclusivamente por meio do consumo. $\mathrm{O}$ abandono da área rural (vilas, unidades de produção familiar) e a imposiçáo do urbano como solução (falaciosa) para a demanda histórica de provisão de infraestrutura e de equipamentos básicos (saúde, educação, saneamento) para o campesinato são acompanhados pela desvalorização das práticas produtivas e de lazer 
tradicionais da regiáo (agricultura, pesca, caça), usadas para justificar a degradação do meio biofísico em nome do progresso que não alcança todos os grupos sociais da mesma forma.

Em paralelo, a polarização entre o crescimento quase instantâneo da população da cidade e as exigências de qualificação da mineradora e suas subsidiárias criaram uma massa de habitantes excluídos das oportunidades abertas pela racionalidade industrial, ao mesmo tempo que a valorização da terra desestimulou o trabalho agrícola, e ao reestruturar a produção rural resultou em êxodo rural e na degradação das condiçôes de vida desses indivíduos: "É por isso que não gosto muito daqui, porque a gente nunca teve oportunidade de ganhar alguma coisa. Trabalhar pras empresas daqui, não posso contar com elas" (moradora, julho de 2016).

Nesse aspecto, a cidade oferece experiências diferenciadas para os diferentes grupos sociais. Os trabalhadores assalariados a serviço da mineração contam com transporte corporativo, e os novos habitantes que possuem carro próprio usufruem do território de modo completamente diferente do antigo morador rural, que continua sem alternativa de mobilidade ou condiçôes de acesso aos novos equipamentos de saúde e educação, por exemplo, especialmente depois das novas estradas terem sido concluídas. O grupo dos pioneiros que historicamente concentrou a posse da terra ou estabeleceu relaçóes sociais fortes colecionou privilégios econômicos e políticos. O controle da terra permitiu as coalizóes com o setor imobiliário, e as boas amizades viabilizaram a segurança do emprego público e o acesso aos tomadores de decisão. Essas articulaçóes deram a esses grupos sociais alguma capacidade de assumir os custos de conversão da vila em cidade, seja pelo acesso a serviços de saúde e educação particulares, seja pela capacidade de custear os preços dos imóveis da área central, seja pela posse de propriedades na zona rural como forma de lazer.

Os grupos sociais excluídos das oportunidades geradas pela mineração buscam artifícios para se adaptarem à nova realidade; criam estratégias de produção e de lazer relacionadas ao aproveitamento da terra para agricultura urbana de modo a manterem ativa a escala de reprodução da vida cotidiana. Nos discursos dos entrevistados, há fortes referências ao modo de vida tradicional, espacialmente traduzidas em um grande número de pequenas hortas nos quintais de casa e em rápidas incursóes de pesca e caça em áreas próximas, evidenciando a conversáo incompleta do modo de vida rural em urbano, e destacando tais atividades náo apenas como práticas de subsistência, mas também de resistência à imposição da lógica urbana, táo comuns na Amazônia, mas tão negligenciada pelas políticas públicas genéricas:

Entrevista 01: [Por que vocês plantam uma horta?] Pro consumo, né?! Às vezes quando aparece gente pra comprar, a gente vende. Porque pra gente comprar muitas vezes a gente tem, muitas vezes a gente não tem, né?! Então melhor plantar (moradora, agosto de 2016).

Entrevista 02: Eu sempre gostei de plantar. Tomate, cebola, coentro. Lá [antiga moradia da entrevistada] eu morei uma temporada na cidade, aí saiu uma invasão lá na beira do rio, meu marido foi e tirô um pedacinho e a gente fez um barraquinho. Ficava bem próximo mesmo do [rio] Tocantins [...] Gostava demais, já tava acostumada (moradora, agosto de 2016).

Entrevista 03: Aqui o meu marido tem a profissão dele de montador de andaime, só que ele também gosta de caçar, para ir pro mato quando ele tá precisando matar caça [...] Pes- 
car também, ele gosta de pescar, ele mesmo pesca, ele tem rede, essas coisas pra pescar. Aí é bom, quando não dá pra um lado, a gente tenta do outro [...] Ai agora ele veio com essa ideia de fazer essa horta [...] pra tirar pelo menos o do arroz, do feijão [...] É um meio de sobreviver. Um pouco que entrar já dá, né?! (moradora, agosto de 2016).

A gestão municipal, por outro lado, na crença de que a mineração pode sozinha alçar o município a uma posição de maior destaque dentro da rede urbana regional, cria obstáculos à continuidade de práticas rurais ao assumir a oposiçáo clássica entre universos rural e urbano, absolutamente irreal no contexto de Canaã dos Carajás. Essa situação é ilustrada pelo caso da feira de produtores agrícolas, que reúne produtores rurais de Canaã dos Carajás e localidades próximas, principalmente de Parauapebas, aos sábados. Eles se reúnem em um espaço próximo à sede da Prefeitura em uma feira de produtos hortifrutigranjeiros, fomentando a economia local e trazendo vitalidade para o espaço público. Contrapondo-se a esta prática já consolidada, a Prefeitura construiu recentemente um grande centro de distribuição que apenas poderá ser ocupado por produtores do município, e pretende terminar com a feira de rua, num claro posicionamento de higienização das práticas "atrasadas" e descaso frente à ideia de que desenvolvimento deriva de codesenvolvimento, de capital humano e ecossistemas múltiplos (JACOBS, 2001).

A invisibilização dos rios, morros e floresta, pela dificuldade de acesso impede o reconhecimento do potencial que essas áreas oferecem para a socialização da população, e da importância social de sua preservação: "Eu vou [no rio], só que é longe. É lá no Pebas [Rio Parauapebas] que nós vamos. Mas o Pebas já tá seco, tá todo cortado, aquele pocinho velho que fica acolá [...]. É só pra andar mesmo, porque peixe mesmo não pega mais não" (entrevista 02, moradora, agosto de 2016). Atualmente a gestão municipal está na fase inicial de elaboração do plano de turismo municipal visando a trazer à tona esses espaços que permanecem ocultos.

Nada paga o bastante quando comparado com a mineração, especialmente em termos de arrecadação tributária, e mesmo quando não é possível absorver toda a mão de obra disponível, opta-se pela reprodução acrítica dos padrôes de vida das grandes cidades, em que trabalhadores vivem distantes do local de trabalho, em que a conservação da natureza é subordinada à urbanização que, ao ser destruída, inviabiliza e exclui grupos sociais que dependiam da biodiversidade para seu sustento. Enquanto o paralelismo entre modernização (industrialização) e as reinvindicações por cidadania foram marcantes em países de capitalismo avançado, no contexto em tela a utopia lefebvriana do direito ao urbano e à cidade ainda é algo imponderável. Seguindo a tendência contemporânea da cidade "neoliberal", gestada pela privatizaçáo dos meios produtivos e pela financeirização da economia, a cidade que ainda está em gênese aceita sem estranhamento a deterioração tanto do homem público quanto da cidade como espaço de sociabilidade.

\section{CONCLUSÃO}

Os resultados apresentados no texto demonstram que é fundamental a articulação das formulaçôes contemporâneas aos estudos sobre urbanização brasileira, dada a forma seletiva como as modernizaçóes acontecem e se constituem em novas 
formas de colonização que facilmente homogeneízam e despolitizam a população. Há necessidade de novas metodologias e recortes de pesquisas mais interdisciplinares e compreensivos para o adequado enquadramento dos processos em curso, de modo que a academia não reforce as falsas dicotomias, a negação da natureza e os mecanismos de colonização, ao caracterizar o território e, em particular, a inserção das cidades em suas regiôes.

Observou-se que o volume de recursos e o ritmo de sua movimentação pelo capital global geram riqueza e exclusão, na medida em que permitem a abertura do território para a ação simultânea de diversas fraçôes do capital (mercantil, produtivo, financeiro) e sua coexistência com formas de vida não capitalistas, sem reconhecerem a diversidade de formaçóes socioespacias que tal coexistência gerou. Além disso, a maneira como as novas oportunidades se articulam com as relaçôes sociais e estruturas de poder já estabelecidas define manifestações não elaboradas pelas teorias formuladas no Norte Global.

O surgimento de novas esferas de consumo e a negação da dimensão pública na vila que se metamorfoseou em cidade e teve sua produção capturada pelo capital financeiro global produzem novas paisagens que conectam dialeticamente as diversas formas de expressão da urbanização capitalista. Contudo, sempre de modo incompleto e seletivo, seguindo a tese de Santos (2008[1979]). A cada modernização, novos pontos ou zonas do espaço são conquistados sobre o espaço neutro, e se tornam uma nova porção do espaço operacional (SANTOS, 2008[1979]). São espaços híbridos, uma vez que são tensionados tanto por fatores político e econômico externos quanto pelas relaçóes e hierarquias de poder que se articulam no âmbito local, como foi evidenciado ao longo do texto.

A falta de conceitos e estruturas de análise, tâo bem apontada por autores pós-coloniais, mantiveram invisibilidades e negaram ou desqualificaram os saberes e/ou práticas anteriores que assumiam a natureza como um componente ativo do processo produtivo. Essa decisão assume a atividade ligada ao grande capital como desejável e prioritária, ainda que seus benefícios sejam capturados por poucos, e nega a possibilidade de criação de cadeias produtivas inovadoras apoiadas no diálogo entre as novas tecnologias e os saberes locais tradicionais conforme defendido por Silva, Diniz e Ferreira (2013), que seriam capazes de promover e articular trabalho novo e trabalho velho (JACOBS, 2001). Essa seria uma forma de promover a inclusão dos grupos sociais não inseridos nas dinâmicas da mineração, imobiliária, ou da grande produção pecuária e reduzir as desigualdades históricas, reconhecendo a necessidade de reprodução da vida e de emancipação da população para a tão sonhada universalização da cidadania.

Além disso, no contexto de Canaã dos Carajás, as dinâmicas globais ligadas ao mercado financeiro, como é o caso de economias orientadas à exportação de commodities, têm sido centrais para a intensificação do processo de urbanizaçáo extensiva, através da produção extraordinária de loteamentos lastreados por capitais oriundos de fundos de investimentos internacionais. Essas novas dinâmicas evidenciam o descolamento entre as mudanças no uso da terra mediadas por interesses de agentes globais e regionais que não possuem vínculos com o que acontece no "chão" da cidade e a esfera da vida cotidiana, esta profundamente impactada pelo projeto de modernização orientado pelo circuito superior, através do efeito-demonstração, que inclui inserção massiva da população na esfera do consumo. Conforme Harvey (2013 [1982]) afirma, a aproximação dos circuitos imobiliário e financeiro determina 
Ana Cláudia Duarte Cardoso é graduada em Arquitetura e Urbanismo pela Universidade Federal do Pará (UFPA); mestre em Planejamento Urbano pela Universidade de Brasília (UnB); doutora em Arquitetura pela Oxford Brookes University, Reino Unido; professora associada na Faculdade de Arquitetura e Urbanismo da UFPA; bolsista de Produtividade em Pesquisa do CNPq.

E-mail: aclaudiacardoso@ gmail.com

Lucas Souto Cândido é graduado e mestrando em Arquitetura e Urbanismo pela Universidade Federal do Pará (UFPA).

E-mail: candido74@hotmail. com

Ana Carolina Campos de Melo é graduada e mestra em Arquitetura e Urbanismo pela Universidade Federal do Pará (UFPA); doutoranda em Economia pela UFPA.

E-mail: carolmelo.08@gmail. com

Artigo recebido em 2 de dezembro de 2016 e aprovado para publicação em 26 de abril de 2017.

Agradecimentos: Os autores agradecem as bolsas de estudo da CAPES e de pesquisa do CNPq, o financiamento do Instituto Tecnológico Vale e da Fundação Vale, a parceria da Prefeitura Municipal de Canaã dos Carajás, a crítica de Rosane Biasotto e dos pareceristas, a revisão da língua portuguesa de Laïs Zumero e a tradução para língua inglesa de Brian Honeyball. a forma como o capital é alocado na terra. Esta molda os investimentos privados e a estruturação geográfica da produção, as divisôes de trabalho e, no limite, a dinâmica dos espaços de reproduçáo.

A adoção das esferas de vida propostas por Lefebvre como estrutura de análise procura evidenciar o quanto as redes urbanas extrapolam em muito o território nacional, ainda que sob a perspectiva de alguns atores sociais, enquanto para outros, em pleno século XXI, ainda nem existe a compreensão da cidade como espaço de direitos. Neste contexto a discussão tanto sobre o acesso à natureza quanto ao acesso à terra deveria ser indissociável da discussão sobre o urbano e a cidade que estão em gênese, sob todos os sentidos.

\section{REFERÊNCIAS}

ACSELRAD, H. A Duração das Cidades: sustentabilidade e risco nas políticas urbanas. Rio de Janeiro: DP\&A, 2001.

. Novas articulaçôes em prol da justiça ambiental. Democracia Viva, v. 3, p. 42-47, 2005.

Ambientalizaçáo das lutas sociais? $\mathrm{O}$ caso do movimento de justiça ambiental. Estudos Avançados, v. 24, n. 68, p. 103-120, 2010a. http://dx.doi.org/10.1590/S010340142010000100010

Cartografia social e dinâmicas territoriais: marcos para o debate? 1. ed. Rio de Janeiro: ETTERN/IPPUR, 2010b.

. MELLO, C. C. A.; BEZERRA, G. N. O que é Justiça Ambiental. Rio de Janeiro: Garamond, 2009.

AUGÉ, M. Não-lugares: introdução a uma antropologia da supermodernidade. Campinas: Papirus, 1994.

BAUMAN, Z. Modernidade líquida. Rio de Janeiro: Jorge Zahar Editores, 2001.

Capitalismo parasitário: e outros temas contemporâneos. Rio de Janeiro: Jorge Zahar Editores, 2010.

BECKER, B. K. Geopolitica da Amazônia: A Nova Fronteira de Recursos. Rio de Janeiro: Jorge Zahar Editores, 1982.

BECKER, B. A Urbe Amazônida. Rio de Janeiro: Garamond, 2013.

BRASIL. Presidência da República. Lei n. 11.952, de 25 de junho de 2009. Dispóe sobre a regularização fundiária das ocupaçôes incidentes em terras situadas em áreas da União, no âmbito da Amazônia Legal; altera as Leis nos 8.666, de 21 de junho de 1993, e 6.015, de 31 de dezembro de 1973; e dá outras providências. Lex: Disponível em: <http://www.planalto.gov.br/ccivil_03/_ato2007-2010/2009/lei/111952.htm>. Acesso em: 8 maio 2017.

BRENNER, N. Theses on Urbanization. Public Culture, v. 25, n. 1 69, p. 85-114, 2013. http://dx.doi.org/10.1215/08992363-1890477.

(Ed.). Implosions/Explosions: Towards a Study of Planetary Urbanization. Berlin: Jovis, 2014.

; SCHMID, C. Towards a new epistemology of the urban? City, v. 19, n. 2-3, p. 151-182, abr. 2015. http://dx.doi.org/10.1080/13604813.2015.1014712

CARdosO, A. C. et al. Rios e diversidade sócio espacial na Amazônia Oriental. In: ENCONTRO NACIONAL DA ANPARQ, 4., Porto Alegre, 2016. Anais... Porto Alegre: ANPARQ, 2016. Disponível em: <https://enanparq2016.files.wordpress. com/2016/09/s04-04-cardoso-a-et-al.pdf>. Acesso em: 8 maio 2017. 
CARLOS, A. F. O Espaço Urbano: novos escritos sobre a cidade. São Paulo: Labur Ediçóes, 2007.

COELHO, T. P. Projeto Grande Carajás: Trinta anos de desenvolvimento frustrado. Rio de Janeiro: Ibase, 2014. Disponível em: <http://www.uff.br/poemas/files/2014/07/ Coelho-2014-Projeto-Grande-Caraj\%C3\%A1s.pdf>. Acesso em: 8 maio 2017.

COSTA, F. A. Trajetórias Tecnológicas como Objeto de Política de Conhecimento para a Amazônia: uma metodologia de delineamento. Revista Brasileira de Inovação, v. 8, n. 1, p. 35-52, jan./jun. 2009. Disponível em: <http://ocs.ige.unicamp.br/ojs/rbi/article/ view/360>. Acesso em: 8 maio 2017.

DIAGONAL URBANA. Relatório Técnico da Revisão do Plano Diretor Participativo de Canaã dos Carajás (RTPPPCC). Canaã dos Carajás: Diagonal Urbana, 2011.

EMMI, M. F. A Oligarquia do Tocantins e o Domínio dos Castanhais. Belém. UFPA/NAEA, 1999.

FUNDAÇÃO DE AMPARO E DESENVOLVIMENTO DA PESQUISA - FADESP. Relatório de análise da estrutura espacial da cidade de Canaã dos Carajás: padrão de parcelamento do solo, produção de centralidades, mobilidade, mercado de terras e habitacional. Belém: UFPA, 2016.

FERNANDES, D. et al. A formaçâo das elites na Amazônia: diversidade estrutural e estratégias de desenvolvimento regional no século XX. Relatório de Pesquisa (Projeto Edital Universal 2013), 2016.

FERREIRA, J. S. W. São Paulo: o mito da cidade global. 2003. 336 f. Tese (Doutorado em Arquitetura e Urbanismo) - Faculdade de Arquitetura e Urbanismo, Universidade de São Paulo, São Paulo, 2003. Disponível em: <http://www.fau.usp.br/depprojeto/ labhab/biblioteca/teses/ferreira_doutorado_mitocidglobal.pdf $>$. Acesso em: 8 maio 2017.

FURTADO, C. O mito do desenvolvimento econômico. Rio de Janeiro: Paz e Terra, 1974.

HARDT, M.; NEGRI, A. Império. 5. ed. Rio de Janeiro: Record, 2004.

HARVEY, D. Limites do Capital. São Paulo: Boitempo, 2013[1982].

HECKENBERGER, M. J. As cidades perdidas da Amazônia: A floresta tropical amazônica não é tão selvagem quanto parece. Scientific American Brasil, n. 90, nov. 2009. Disponível em: <http://www2.uol.com.br/sciam/reportagens/as_cidades_perdidas_ da_amazonia_7.html>. Acesso em: 8 maio 2017.

INSTITUTO BRASILEIRO DE GEOGRAFIA E ESTATÍSTICA - IBGE. Censo Populacional 2010. Rio de Janeiro: IBGE, 2010.

JACOBS, J. The economy of cities. New York: Random House Inc., 2001.

LE GALÈS, P. Neoliberalism and Urban Change: Stretching a Good Idea Too Far?. Territory, Politics, Governance, v. 4, n. 2, p. 154-172, abr. 2016. http://dx.doi.org/10.1080/21622 671.2016.1165143

LEFEBVRE, H. A produção do espaço. Belo Horizonte: [s.n.], 2006. Disponível em: <http:// www.mom.arq.ufmg.br/mom/arq_interface/1a_aula/A_producao_do_espaco.pdf>. Acesso em: 8 maio 2017.

A Revolução Urbana. 3. ed. Belo Horizonte: Ed. UFMG, 2008[1970].

LEITÁO, K. O. A dimensão territorial do Programa de Aceleração do Crescimento: Um estudo sobre o PAC no estado do Pará e o lugar que ele reserva à Amazônia no desenvolvimento do país. 2009. 285 f. Tese (Doutorado em Arquitetura e Urbanismo) - Faculdade de Arquitetura e Urbanismo, Universidade de São Paulo, São Paulo, 2009. Disponível em: <http://www.teses.usp.br/teses/disponiveis/16/16139/tde-04032010-140034/pt-br. php>. Acesso em: 8 maio 2017.

LOGAN, J. R.; MOLOTCH, H. L. Urban Fortunes: The Political Economy of Place. Los Angeles: University of California Press, 1987. 
MELO, A. C. Modernização e Transformaçôes recentes nos processos intra-urbanos no sudeste do Pará. 2015. 139 f. Dissertação (Mestrado em Arquitetura e Urbanismo) Faculdade de Arquitetura e Urbanismo, Universidade Federal do Pará, Belém, 2015.

MONTE-MÓR, R. L. M. Urbanização extensiva e lógicas de povoamento: um olhar ambiental. In: SANTOS, M.; SILVEIRA, M. L.; SOUZA, M. A. A. Território, globalização e fragmentação. São Paulo: Hucitec, ANPUR, 1994. p. 169-181.

. Urbanizaçáo, Sustentabilidade, Desenvolvimento: complexidades e diversidades contemporâneas na produção do espaço urbano: In: COSTA, G. M.; COSTA, H. S. M.; MONTE-MÓR, R. L. M. (Org.). Teorias e Práticas Urbanas: condiçóes para a sociedade urbana. Belo Horizonte: C/Arte, 2015. p. 55-70.

MOURA, R. A dimensão urbano-regional na metropolização contemporânea. EURE, v. 38, n. 115, p. 5-31, set. 2012. https://doi.org/10.4067/s0250-71612012000300001

MUXÍ, Z. Ciudad Global. Barcelona: Gustavo Guili, 2004.

NUNES, E. A Gramática Política do Brasil. Rio de Janeiro, Brasília: Zahar, ENAP, 1997.

PARÁ. Secretaria de Estado de Indústria, Comércio e Mineração. Balança Comercial: Desempenho do Comércio Exterior Paraense. Belém: Investpará, 2014.

PECK, J. Cities beyond Compare? Regional Studies, v. 49, n. 1, p. 160-182, dez. 2014. http:// dx.doi.org/10.1080/00343404.2014.980801

POLANYI, K. A grande transformação: as origens da nossa época. 2. ed. Rio de Janeiro: Elsevier, 2000[1945].

PREFEITURA MUNICIPAL DE CANAÃ dOS CARAJÁS - PMCC. Lei n. 557 de 03/12/2012. Plano Diretor Municipal de Canaã dos Carajás. . Sistema viário. Shapefile. Canaã dos Carajás: PMCC, 2015.

ROBINSON, J. Cities in a World of Cities: The Comparative Gesture. International Journal of Urban and Regional Research, v. 35, n. 1, p. 1-23, jan. 2011. http://dx.doi.org/10.1111/ j.1468-2427.2010.00982.x

; PARNELL, S. Traveling Theory: Embracing Post-Neoliberalism through Southern Cities. In: BRIDGE, G.; WATSON, S. (Ed.). The New Blackwell Companion To The City. [S.1.: s.n.], 2012. p. 521-531. http://dx.doi.org/10.1002/9781444395105.ch46

ROY, A. Slumdog Cities: Rethinking Subaltern Urbanism. International Journal of Urban and Regional Research, v. 35, n. 2, p. 223-238, 11 mar. 2011. http://dx.doi.org/10.1111/ j.1468-2427.2011.01051.x

SANTOS, M. O Trabalho do Geógrafo no Terceiro Mundo. 2. ed. São Paulo: Hucitec, 1986.

. Espaço Dividido: os dois circuitos da economia urbana dos países subdesenvolvidos. 2. ed. Sáo Paulo: Edusp, 2008[1979].

SILVA, H., DINIZ, S., FERREIRA, V. Circuitos da Economia Urbana e economia dos setores populares na fronteira amazônica: o cenário atual no sudeste do Pará. Revista Brasileira de Estudos Urbanos e Regionais, v. 15, n. 2, p. 61-76, nov. 2013. https://doi. org/10.22296/2317-1529.2013v15n2p61

SMITH, N. Desenvolvimento Desigual. Rio de Janeiro: Bertrand Brasil, 1988.

STORPER, M. The Neo-liberal City as Idea and Reality. Territory, Politics, Governance, v. 4, n. 2, p. 241-263, abr. 2016. http://dx.doi.org/10.1080/21622671.2016.1158662

TUAN, Y-F. Espaço e Lugar: a perspectiva da experiência. Londrina: Eduel, 2013.

VALE S. A. Complexo S11D, 2016. Disponível em: <http://www.vale.com/hotsite/PT/ Paginas/Home.aspx>. Acesso em: 8 maio 2017.

WATSON, V. 'The planned city sweeps the poor away...': Urban planning and 21st century urbanization. Progress in Planning, v. 72, n. 3, p. 151-193, out. 2009. http://dx.doi. org/10.1016/j.progress.2009.06.002 